\title{
A study of thyroid dysfunction in dysfunctional uterine bleeding
}

\author{
Santosh Kumar Verma ${ }^{1 *}$, Anita Pal $^{1}$, Saroj Jaswal ${ }^{2}$
} ${ }^{1}$ Department of Obstetrics and Gynecology, ${ }^{2}$ Department of Biochemistry, KNH, IGMC, Shimla, Himachal Pradesh,
India

Received: 13 March 2017

Accepted: 07 April 2017

\section{*Correspondence:}

Dr. Santosh Kumar Verma,

E-mail: drsantoshverma111@gmail.com

Copyright: (c) the author(s), publisher and licensee Medip Academy. This is an open-access article distributed under the terms of the Creative Commons Attribution Non-Commercial License, which permits unrestricted non-commercial use, distribution, and reproduction in any medium, provided the original work is properly cited.

\section{ABSTRACT}

Background: The objective of the study was to evaluate the prevalence of thyroid dysfunction in dysfunctional uterine bleeding and to assess the menstrual and endometrial pattern in women with thyroid disorders.

Methods: The present study was conducted on 200 patients who presented with dysfunctional uterine bleeding in gynecology OPD.

Results: Among the 200 women 39 (19.5\%) had hypothyroidism, 2 (1\%) had hyperthyroidism and $159(79.55 \%)$ were euthyroid. Menorrhagia was the most common menstrual disorder in hypothyroidism and oligomenorrhoea in hyperthyroidism. In the present study $74.3 \%$ patients had proliferative endometrium, $26.3 \%$ secretory endometrium, in hypothyroid patients and secretory endometrium in $2(1 \%)$ hyperthyroid patients. A woman with hypothyroidism, commonly presents with anovulation and unopposed oestrogen activity causes endometrial hyperplasia which may outgrow the blood supply and may cause local areas of necrosis and breakdown and produces bleeding.

Conclusions: The menstrual irregularities are significantly more frequent in patients with thyroid dysfunction and menorrhagia was the commonest menstrual abnormality. The study concludes that biochemical evaluation of thyroid function should be made mandatory in all cases of abnormal uterine bleeding and this would avoid unnecessary surgeries and exposure to hormones.

Keywords: Abnormal uterine bleeding, Dysfunctional uterine bleeding, Menorrhagia, Oligomenorrhoea, Thyroid dysfunction

\section{INTRODUCTION}

DUB is a symptom complex that includes any condition of abnormal uterine bleeding in the absence of pregnancy, neoplasm, infection or other intrauterine lesion. Such bleeding is most often the result of endocrinologic dysfunction that inhibits normal ovulation. $^{1}$

Dysfunctional uterine bleeding is best defined as abnormal bleeding from the uterus in the absence of organic disease of the genital tract. The term DUB applies to any abnormal uterine bleeding, including disturbances of the menstrual cycle, regular or irregular uterine bleeding and alterations in amount and the duration of menstrual loss, but most commonly implies to excessive regular menstrual bleeding or essential menorrhagia. DUB is not one condition with one etiology, but is a group of disorders characterized by the dysfunction of the uterus, ovary, pituitary, hypothalamus or other part of reproductive system which results in abnormal or excessive uterine bleeding. In clinical practice the precise nature of the dysfunction is often not determined and the diagnosis of DUB is usually made by exclusion of organic disease of the genital tract. ${ }^{2}$

The International Federation of Gynaecology and Obstetrics in November 2010, accepted a new 
classification system for causes of AUB in the reproductive years. The system based on the acronym PALM COEIN (polyps, adenomyosis, leiomyoma, malignancy and hyperplasia-coagulopathy, ovulatory disorders, endometrial causes, iatrogenic, not classified) was developed in response to concerns about the design and interpretation of basic science and clinical investigation that relates to the problem of AUB. ${ }^{3}$

Dysfunctional uterine bleeding is one of the most common and significant gynaecological complaints and is seen in about $10-15 \%$ of women attending the gynaecological clinic.

\section{According to aetiology DUB is classified as}

- Primary: Pathology in endometrium or hypothalamopituitary-ovarian-endometrial-axis (ovulatory and anovulatory).

- Secondary: cause detected outside the hypothalmopituitary-ovarian-endometrial axis (endocrinopathies, hematological, vascular disease and liver disorders). Iatrogenic: caused by drugs, irregular hormone intake and/or IUCD. ${ }^{4}$

Thyroid dysfunction is a cause of nonstructural AUB. Thyroid is closely linked with the process of ovarian maturation. ${ }^{5}$ Thyroid disorders are more common in women than in men and in older adults compared with younger age groups. Hypothyroidism is associated with a wide spectrum of reproductive disorders ranging from abnormal sexual development, menstrual irregularities and infertility. The impact of hypothyroidism on the menstrual cycle has been identified since the 1950s and leads to changes in cycle length and blood flow. Thyroid autoimmunity has been shown to have association with various kinds of thyroid dysfunction. ${ }^{6}$

Thyroid disorder is one of the endocrinopathies associated with disturbance in menstrual functions. The reported incidence of subjective menorrhagia in myxedema varies from $32-80 \%$ and menorrhagia may not infrequently be the presenting complaint. Hyperthyroidism, in contrast is associated with oligomenorrhoea and amenorrhea which are in proportion to the severity of thyrotoxicosis. ${ }^{7}$

Both conditions respond to proper therapy when the thyroid gland is the cause of the abnormality. TSH is a very sensitive indicator of thyroid action at the tissue level because it is dependent on the pituitary exposure to $\mathrm{T}_{4}{ }^{8}$

\section{METHODS}

Study was conducted at Kamla Nehru state Hospital For Mother and Child, IGMC, Shimla, Two hundred patients with dysfunctional uterine bleeding during reproductive age group attending the out patient department of
Obstetrics and Gynecology were selected for the study after permission from ethical committee.

After informed consent detailed history of all patients was taken including the menstrual history.

The menstrual cycles were considered normal if the patients fulfill the following criteria

- $\quad$ The duration of menstrual bleeding was between 2-7 days.

- The menstrual flow was not heavy and contained by two perineal pads.

- There is no expulsion of sizeable clots during menstruation.

- The frequency of the menstrual cycle is constant ranging from 21 to 35 days.

Detailed obstetric history was taken.

Past history was taken in detail including contraception history, history of drug or hormone intake, IUCD, any disease and any bleeding disorder.

Detailed surgical and medical history with special reference to symptoms of 'thyroid dysfunctions e.g. excessive weight gain/loss, cold/heat intolerance, easy fatiguability /irritability, palpitations, hoarseness of voice, diarrhea etc, were enquired.

General physical, systemic and local examination was done.

The following investigations were done in all the patients:

Complete haemogram, urine examination and TFT and ultrasonography were done. Every patient underwent D and $\mathrm{C}$ in premenstrual phase or first day of cycle. The endometrial curettings were sent in $10 \%$ formalin to the Department of Pathology IGMC, Shimla for histopathological examination.

Thyroid stimulating hormone was measured by Dia Metra Kit in the department of Biochemistry 1GMC Shimla. $5 \mathrm{ml}$ of venous blood was collected under all aseptic precautions. Serum was separated and stored in refrigerator at $2-8^{\circ} \mathrm{C}$. The data was collected and statistically analysed.

It is immune enzymatic calorimetric method for quantitative determination of thyroid stimulating hormone. An antibody specific to beta chain of human TSH molecule is immobilized on micro well plates and other antibodies to the TSH molecule are conjugated with Horse-radish peroxide. TSH from the sample is bound to the plates. After a washing step HRP conjugate is added. After a second washing step, substrate were added. The enzymatic reaction will be proportional to the amount of $\mathrm{TSH}$ in the sample. The reaction will be terminated by 
adding stopping solution. The absorbance will be measured on a plate reader at $450 \mathrm{~nm}$. This sensitive assay can detect TSH concentrations as low as $0.01 \mu \mathrm{IU} / \mathrm{L}$. The normal range is usually $0.45-4.5 \mu \mathrm{IU} / \mathrm{L}$.

\section{RESULTS}

The mean age of the patients was $38 \pm 7$ years. Majority of the patients belonged to the age group of 41 to 50 years $(42.5 \%)$. The least common age group was of those between 20 to 30 years $(19 \%)$.

Table 1: Distribution of patients according to age $(\mathrm{N}=\mathbf{2 0 0})$.

\begin{tabular}{|lll|}
\hline Age in years & No. of cases & Percent \\
\hline $20-30$ & 38 & 19.00 \\
\hline $31-40$ & 77 & 38.50 \\
\hline $41-50$ & 85 & 42.50 \\
\hline
\end{tabular}

The mean parity was $2.85 \pm 0.53$. Majority of the cases were between para 2 to para 5 .
The most common complaint was menorrhagia $(47.5 \%)$ followed by metrprrhagia (25\%). Polymenorrhagia, Oligomenorrhoea and hypomenorrhoea were present in $8 \%, 6 \%$ and $3.5 \%$ of patients respectively.

Table 2: Distribution of patients according to menstrual pattern $(\mathrm{N}=\mathbf{2 0 0})$.

\begin{tabular}{|ll|l|}
\hline Presenting complaint & No. of patients & Percent \\
\hline Menorrhagia. & 95 & 47.50 \\
\hline Metrorrhagia & 50 & 25.00 \\
\hline Menometrorrhagia & 20 & 10.00 \\
\hline Polymenorrhagia & 16 & 8.00 \\
\hline Oligomenorrhoea & 12 & 6.00 \\
\hline Hypomenorrhoea & 07 & 3.50 \\
\hline
\end{tabular}

There were $11 \%$ patients with ultrasonographic diagnosis of endometrial hyperplasia with endometrial thickness of more than $14.1 \mathrm{~mm}$, were correlated with histopathology and all of the 11 patients had confirmed endometrial hyperplasia on histopathological examination.

Table 3: Distribution of patients according to thyroid status in relation to age groups.

\begin{tabular}{|lllll|}
\hline Thyroid status & $\begin{array}{l}\text { Age in years } \\
\text { Age group I 20-30 } \\
\text { years no. (\%) }\end{array}$ & $\begin{array}{l}\text { Age group II 31-40 } \\
\text { years no. (\%) }\end{array}$ & $\begin{array}{l}\text { Age group III 41-50 years } \\
\text { no. (\%) }\end{array}$ & Total \\
\hline Euthyroid & $33(20.70$ & $65(40.00)$ & $61(38.30)$ & $159(79.50)$ \\
\hline Hypothyroid & $08(12.50)$ & $15(38.40)$ & $16(41.00)$ & $39(19.50)$ \\
\hline Hyperthyroid & $02(100.00)$ & 00 & 00 & $02(01.00)$ \\
Total & $\mathbf{4 3 ( 2 1 . 5 0 )}$ & $\mathbf{8 0}(\mathbf{4 0 . 0 0 )}$ & $\mathbf{7 7}(\mathbf{3 8 . 7 0})$ & $\mathbf{2 0 0}$ \\
\hline
\end{tabular}

Table 4: Distribution of patients with thyroid dysfunction and relation of endometrial pathology $(\mathrm{N}=200)$.

\begin{tabular}{|c|c|c|c|c|c|c|}
\hline \multirow[b]{2}{*}{ Thyroid status } & \multicolumn{5}{|c|}{ Endometrial Pathology } & \multirow[b]{2}{*}{$\begin{array}{l}\text { Total No. } \\
(\%)\end{array}$} \\
\hline & $\begin{array}{l}\text { Proliferative } \\
\text { no. }(\%)\end{array}$ & $\begin{array}{l}\text { Secretory } \\
\text { no. }(\%)\end{array}$ & $\begin{array}{l}\text { Endometrial } \\
\text { hyperplasia } \\
\text { no. }(\%)\end{array}$ & $\begin{array}{l}\text { Irregular } \\
\text { ripening } \\
\text { no. }(\%)\end{array}$ & $\begin{array}{l}\text { Irregular } \\
\text { shedding } \\
\text { no. }(\%)\end{array}$ & \\
\hline Hypothyroid & $29(74.30)$ & $07(17.90)$ & $03(07.62)$ & 00 & 00 & $39(19.50)$ \\
\hline Hyperthyroid & 00 & 02 & 00 & 00 & 00 & $2(01.00)$ \\
\hline Euthyroid & $93(58.40)$ & $51(32.00)$ & $10(06.20)$ & $02(01.20)$ & $03(01.80)$ & $159(79.50)$ \\
\hline Total & 122 & 60 & 13 & 02 & 03 & 200 \\
\hline
\end{tabular}

Table 5: The patients with dysfunctional uterine bleeding according to ultrasonography in relation to histopathology $(\mathrm{N}=200)$.

\begin{tabular}{|lllll|}
\hline Histopathology & $\begin{array}{l}\text { Endometrial Thickness } \\
\text { <than } \mathbf{8 m m})\end{array}$ & $\begin{array}{l}\mathbf{8 . 1} \text { to } \mathbf{1 4 m m} \\
\text { no. }(\mathbf{\%})\end{array}$ & $\begin{array}{l}\text { >than } \mathbf{1 4 . 1 m m} \\
\text { no. }(\mathbf{\%})\end{array}$ & Total \\
\hline Proliferatiive & $94(65.73)$ & $28(63.60)$ & -- & $122(61.00)$ \\
\hline Secretory & $45(31.46)$ & $15(32.60)$ & -- & $60(30.00)$ \\
\hline Endometrial hyperplasia & $01(0.60)$ & $01(02.17)$ & $11(100.00)$ & $13(06.50)$ \\
\hline Irregular ripening & $01(0.60)$ & $01(02.17)$ & -- & $02(01.00)$ \\
\hline Irregular Shedding & $02(1.30)$ & $01(02.17)$ & -- & $03(01.50)$ \\
\hline Total & $\mathbf{1 4 3}$ & $\mathbf{4 6}$ & $\mathbf{1 1}$ & $\mathbf{2 0 0 . 0 0}$ \\
\hline
\end{tabular}

Sensitivity-100\% (71-100), positive predictive value-68.75 (42.88)

Specificity-97.3\% (93-99), negative predictive value-100 (98-100) 
Table 6: Treatment and follow up of patients of dysfunctional utrine bleeding with thyrid dysfunction $(\mathrm{N}=41)$.

\begin{tabular}{|llll|}
\hline Antithyroid & & Hypothyroidism no. (\%) & Hyperthyroidism no. $(\%)$ \\
\hline Thyroxine only & & - & $02(100)$ \\
\hline Responded & $\begin{array}{l}0-6 \text { months Thyroxine } 25-50 \mu \mathrm{g} / \text { antithyroid } \\
\text { drugs }\end{array}$ & $36(92.30)$ & $29(74.35 \%)$ \\
\hline & $6.1-12$ months thyroxine $75-100 \mu \mathrm{g}$ & $07(17.94)$ & \\
\hline Not responded & & $03(07.60)$ & \\
\hline
\end{tabular}

In the present study, the sensitivity of ultrasonography was $100 \%$ (71-100) and specificity was $97.35 \%(93-99)$. Positive predictive value was $68.75 \%(41-88)$ and negative predictive value was $100 \%(98-100)$.

$79.5 \%$ of patients were euthyroid. Hypothyroidism was more common in age group of $31-40$ years $(38.4 \%)$ and $41-50$ years $(41 \%)$. There were only $2(1 \%)$ hyperthyroid cases and they were in the age group of 21-30 years.

In hypothyroid patients $29(74.3 \%)$ had proliferative endometrium and in $2(1 \%)$ cases of hyperthyroidism had secretory endometrium. Out of euthyroid patients 93 $(58.4 \%)$ had proliferative and $51(32 \%)$ had secretory endometrium. 39 (19.5\%) patients were found to have subclinical hypothyroidism and $2(1 \%)$ had hyperthyroid after thyroid function test.

All of the 39 (19.5\%) hypothyroid patients were put on thyroxine $25-50 \mu \mathrm{g} / \mathrm{day}$ for six months. In 29 (74.3\%) patients the TSH level fell down to normal level within six months after the initiation of treatment. 7 (17.94\%) patients required a dose of $50-100 \mu \mathrm{g} /$ day for a period of upto one year for the restoration of their menstrual function. The remaining $3(7.6 \%)$ patients were given antifibrinolytics and hormones in addition to thyroxine but they did not respond to the medical treatment and their hysterectomy was done. Both the hyperthyroid patients resumed their menstrual pattern within three months after taking antithyroid drugs. After the correction of menstrual dysfunction these patients were attached with medicine department. One patient was also an habitual aborter in addition to her menstrual dysfunction, who conceived four months after receiving the thyroxine and delivered a full term baby.

\section{DISCUSSION}

Dysfunctional uterine bleeding (DUB) is one of the most commonly encountered conditions in the OPD. Diagnosis of DUB is by exclusion. It is more common in fourth to fifth decades of life or in perimenopausal age group. ${ }^{3}$ In present study, most of the AUB patients were in the age group of 41 to 50 years $(42.50 \%)$ followed by 31 to 40 years $(38.50 \%)$. N Bhavani et al observed that most of the AUB patients were in the age group of 41 to 50 years (40\%) followed by 31 to 40 years (37\%). ${ }^{9} 84 \%$ of patients were multipara. Pilli et al also reported that DUB was seen in $87 \%$ multipara, $7 \%$ primipara and $6 \%$ in nulliparous women. ${ }^{10}$ Menorrhagia followed by metrorrhagia was the most common menstrual complaint. According to Talukdar et al, the dominant menstrual problem in patients with abnormal uterine bleeding was menorrhagia in $44.44 \% .^{3}$ In the present study, $57.5 \%$ patients had laprosterilization. The theory of increased bleeding is that delivery of hormones from the ovaries to the uterus is impaired. Ovarian functions are deficient since mid luteal progesterone levels decline significantly following this surgery.

In present study $79.55 \%$ patients were euthyroid. $19.5 \%$ patients were hypothyroid in the age group of 31-50yrs and $1 \%$ of the patients were hyperthyroid in the age group of 20-30 years. According to Sowers et-al 90.4\% were euthyroid, $6.2 \%$ hypothyroid and $3.2 \%$ hyperthyroid in perimenopausal age group. ${ }^{11}$ In mid aged women, there was a $9.6 \%$ prevalence of TSH values outside the euthyroid range and TSH levels were associated with bleeding length. Sangeeta Pahwa et al observed in their study that $22 \%$ of cases were hypothyroid, $2 \%$ hyperthyroid and $76 \%$ euthyroid. ${ }^{12}$ Hyperthyroidism reduces menstruation and hypothyroidism causes menorrhagia. Scott and Mussay observed abnormal menstrual pattern in $56 \%$ of myxoedematous patients similar to the present study where menorrhagia and metrorrhagia combined constituted $58.95 \%$ of the abnormal pattern in patients with hypothyroidism. ${ }^{13}$ Kaur et al observed in their study that $85 \%$ of the patients with abnormal uterine bleeding were euthyroid, $14 \%$ hypothyroid and $1 \%$ hyperthyroid. ${ }^{14}$ Main menstrual complaint in hypothyroid patients was menorrhagia in $64.3 \%$ and hypomenorrhoea in $100 \%$ hyperthyroid patients.

Suspicion of hypothyroidism may be delayed in elderly patients because symptoms such as fatigue and constipation and other elderly manifestations of thyroid failure may be attributed to aging itself. Accoring to Goldsmith $70 \%$ of patients with hypothyroidism had proliferative and $20 \%$ had secretory endometrium. ${ }^{15,16} \mathrm{In}$ a study by Padmaleela et al, there was proliferative endometrium in both hypothyroidism and hyperthyroidism patients and secretory endometrium was found in $26.7 \%$ of hypothyroid patients. A study by Kaur $\mathrm{T}$ et al, revealed $64.3 \%$ hypothyroid patients had proliferative endometrium, $21.4 \%$ had endometrial 
hyperplasia and rest $14.3 \%$ had secretory endometrium. ${ }^{14}$ Ajmani A K et al observed that hypothyroid patients mainly had proliferative endometrium $(42.85 \%)$ whereas hyperthyroid had atrophic endometrium $(60 \%){ }^{6}$

In present study, also $74.3 \%$ had proliferative endometrium, $26.3 \%$ secretory endometrium in hypothyroid patients. All the hypothyroid patients were put on Thyroxine $74.35 \%$ responded to dose of 25 $50 \mu \mathrm{g} /$ day within 6 months and menstrual cycles became normal. $17.94 \%$ needed treatment for $6-12$ months with the dose of $75-100 \mu \mathrm{g} /$ day. Ross et al reported that, in patients with myxoedema, after treatment with dessicated thyroid menstrual cycles became regular. ${ }^{7}$

According to Wilansky et al in patients of menorrhagia and hypothyroidism menorrhagia disappeared within 3-6 months and did not reappear in one to three yrs of the follow up after 1- thyroxine treatment. ${ }^{17}$ According to the study done by Talasila et al out of 100 patients with DUB $10(10 \%)$ of the patients were hypothyroid and $1(1 \%)$ patient was hyperthyroid. ${ }^{18}$ All the $11(100 \%)$ of the patients with thyroid disorders responded promptly to the medical treatment.

\section{CONCLUSION}

The menstrual irregularities most often seen in patients with dysfunctional uterine bleeding are menorrhagia metorrhagia and menometrorrhagia in patients with hypothyroidism. In hyperthyroidism irregularity seen is hypomenorrhoea. Thyroid dysfunction should be considered in the evaluation of dysfunctional uterine bleeding especially in women of age greater than or equal to 30 yrs. Thyroid disorder is the most common and treatable cause of DUB. As there is high incidence of thyroid dysfunction in our area, evaluation of thyroid in abnormal uterine bleeding would also avoid unnecessary surgeries and exposure to hormones.

Funding: No funding sources

Conflict of interest: None declared

Ethical approval: The study was approved by the Institutional Ethics Committee

\section{REFERENCES}

1. Butler WJ. Normal and abnormal uterine bleeding.in Rock JA and Jones HW. Telinde's operative gynaecology. $9^{\text {th }}$ edition. PhiladelpShia:Lippinocot Williams and Wilkins;2003:457-78.

2. Davey DA. Dysfunctional uterine bleeding. In Charles R Whitfield Textbook of obstetrics and gynaecology for postgraduates .5 th edition. printed by Bombay Oxford University Press, Delhi;1995:590-607.

3. Talukdar B, Mahela S. Abnormal uterine bleeding in perimenopausal women: correlation with sonographic findings and histopathological examination of hysterectomy specimen. J Mid-Life Health. 2016;7:73-7.

4. Lopez J. Pathophysiology of dysfunctional uterine bleeding. In: Purandare CN, Khadilkar S. Dysfunctional uterine bleeding - An update. First edition. New Delhi. Jaypee Brothers;2004:16-23.

5. Sharma N, Sharma A. Thyroid profile in menstrual disorders. JK Sci. 2012;14(1):14-7.

6. Ajmani NS, Sarbhai V, Yadav N, Paul M, Ahmad A, Ajmani AK. Role of thyroid dysfunction in patients with menstrual disorders in tertiary care center of walled city of Delhi. J Obstet Gynaecol India. 2016;66(2):115-9.

7. Ross GT, Scholz DA, Lambert EH, Geraci. Severe uterine bleeding and degenerative skeletal muscle changes in unrecognized myxoedema. J Clin Endocrinol. 1958;18:492-500.

8. Speroff L, Fritz MA. Reproduction and thyroid . In: clinical gynaecologic endocrinology and Infertility. 7th Ed. Philadelphia:Lippincott Williams \& Wilkins; 2005:805-821

9. Bhavani N, Sathineedi A, Chippa S, ReddyVSP. A study of correction between abnormal uterine bleeding and thyroid dysfunction. International $\mathbf{J}$ Recent Trends Sci Tech. 2015;14(1):131-5.

10. Pilli GS, Sethi B, Dhaded AV, Mathur PR, Dysfunctional uterine bleeding. J Obstet Gynaecol India. 2001;52(3):87-9.

11. Sowers M, Luborsky J, Perdue C et al.thyroid stimulating Hormone(TSH)concentrations and menopausal status in women at the mid-life. J Clin Endocrinol. 2003;58:340-7.

12. Pahwa S, Shailja G,Jasmine K. Thyroid dysfunction in dysfunctional uterine bleeding. J Adv Research Biologic Sci. 2013;5(1):78-83.

13. Scott JC, Mussey E. Menstrual patterns in myxoedema.Am J Obstet Gynaecol. 1964;90:161-5.

14. Kaur T, Aseeja V, Sharma S. Thyroid Dysfunction in dysfunctional uterine bleeding. Webmed Central Obstet Gynaecol. 2011;2(9):002235.

15. Goldsmith RE, Sturgis SH, Lerman J, Stanbury JB Menstrual pattern in thyroid disease. J Clin Endocrinol. 1952;12:846-55.

16. Padmaleela K, Thomas V, Lavanya KM, Kiranmai D. Thyroid disorders in dysfunctional uterine bleeding (DUB) among reproductive age group women-a cross-sectional study in a territory care hospital in Andhra Pradesh India. Int J Med Pharma Sci. 2013;(1):41-6.

17. Wilansky DL, Greisman B. Early hypothyroidism in patients with menorrhagia. Am J obstet. Gynaecol 1989;160:673-77.

18. Sruthi T, Shivanna S, Gopal N. Prevalence of hypothyroidism in patients with provisional Diagnosis of DUB. J Eval Medic Dent Sci. 2014;3(11):2967-72.

Cite this article as: Verma SK, Pal A, Jaswal S. A study of thyroid dysfunction in dysfunctional uterine bleeding. Int J Reprod Contracept Obstet Gynecol 2017;6:2035-9. 